\title{
Entendeu ou quer que eu desenhe? Os desenhos na pesquisa com crianças e sua inserção nos textos antropológicos
}

Do you understand or want me to draw? Drawings in research with children and their insertion in anthropological texts

\author{
Emilene Leite de Sousa' \\ https://orcid.org/0000-0003-2608-6677 \\ emilene.sousa@ufma.br \\ Flávia Ferreira Pires" \\ https://orcid.org/0000-0003-0572-3542 \\ ffp23279@gmail.com \\ I Universidade Federal do Maranhão - Imperatriz, MA, Brasil \\ " Universidade Federal da Paraíba - João Pessoa, PB, Brasil
}




\title{
Resumo
}

Este artigo analisa a utilização dos desenhos produzidos por crianças em pesquisas e sua inserção nos textos antropológicos, a partir de dois argumentos: o de que a produção de desenhos deveria ser considerada como técnica legítima de pesquisa com crianças; o de que é preciso descrever o processo de produção dos desenhos, deixando claras as condições em que se deu e reforçando sua utilização em conjunto com outras técnicas de pesquisa. Para além dessa dupla linha argumentativa, tecemos uma crítica à reduzida relevância que se dá aos desenhos - no que se refere a sua pouca inserção nos textos antropológicos. Neste artigo analisamos um conjunto de textos a partir dos seguintes aspectos: a) sua afirmação da importância dos desenhos para os achados da pesquisa; b) a descrição dos processos de produção dos desenhos; e c) se há a inserção dos desenhos no texto e de que maneira essa inserção é feita.

Palavras-chave: desenhos infantis; técnica de pesquisa; pesquisa com criança; textos antropológicos.

\begin{abstract}
This article analyzes the use of drawings produced by children in research and their insertion in anthropological texts, based on two arguments: that the production of drawings should be considered as a legitimate research technique with children; that it is necessary to describe the production process of the drawings, making clear the conditions in which they occurred and reinforcing their use in conjunction with other research techniques. In addition to this double line of argument, we criticize the reduced relevance that is given to drawings - with regard to their little insertion in anthropological texts. In this article, we analyze a set of texts based on the following aspects: a) their affirmation of the importance of drawings for the research findings; b) the description of the production processes of the drawings; and c) if the drawings are inserted in the text and how this insertion is done.
\end{abstract}

Keywords: children's drawings; technique; research with children; anthropological texts. 


\section{Apresentação}

Este artigo tem como objetivo analisar a utilização dos desenhos produzidos por crianças em pesquisas e sua inserção nos textos antropológicos. Ele parte da observação de que as pesquisas realizadas com crianças que fazem uso do desenho como técnica argumentam, em sua maioria, em favor do desenho como um importante artifício para a construção dos caminhos da pesquisa e dos dados conclusivos. No entanto, temos algumas ressalvas sobre como isso é feito, que ficarão claras ao longo do texto.

Muitos trabalhos antropológicos terminam por colocar os desenhos em segundo plano sem lhes dar a devida importância. Isso se dá através: 1) do posicionamento dos desenhos, muitas vezes em anexos ou completamente ausentes; 2) do seu tamanho reduzido, comprometendo a visualização; 3) da ausência de referência a eles no decorrer dos textos; 3 ) da falta da descrição minuciosa do seu processo de elaboração; 4) da falta de um desenvolvimento das implicações epistemológicas decorrentes dos seus resultados. Todos esses problemas acabam sendo um impedimento para que o desenho das crianças seja plenamente utilizado, possibilitando uma compreensão da técnica de pesquisa como importante para alcançar percepções de crianças em contextos diversos.

Com base nisso, este artigo investiga o modo como os desenhos têm sido utilizados nos textos antropológicos. Sugerimos que o desenho é uma técnica eficaz de pesquisa, grande aliada nas investigações com crianças, cuja importância estaria no auxílio à manifestação das "vozes" de crianças ${ }^{1}$ - menores ou maiores - na construção retórica lúdica e imagética de suas percepções.

1 Sabemos como a questão de dar voz aos chamados nativos é complexa do ponto de vista antropológico. Ela se torna ainda mais delicada quando tratamos de crianças, uma vez que, para nós, elas podem falar e devem ser ouvidas enquanto sujeitos plenos, mas do ponto de vista jurídico essa autonomia não está franqueada a esse grupo social considerado tutelado. Para além disso, a antropologia hermenêutica ou pós-moderna abalou toda a nossa suposta segurança em falar a partir do outro. Dar voz implica franquear a palavra a quem não tem essa possibilidade. É uma permissão dada por quem está em condições de poder a um grupo considerado subalterno. É importante lembrar, no entanto, que as crianças sempre tiveram vozes, nós, os acadêmicos, é que não tínhamos condições (ou não nos era interessante) de escutá-las. Para um debate aprofundado sobre a questão das vozes das crianças sugerimos a leitura do artigo "Giving voice to children's voice" de Allison James (2008). 
É importante lembrar que as antropólogas² parecem se sentir atraídas a usar a técnica do desenho ao mesmo tempo que temem não saber como utilizá-la corretamente. Tememos tirar conclusões apressadas, tememos um certo colonialismo na interpretação dos traços dos nativos, interpretando seus desenhos por eles, e tudo isso também pode contribuir para essa evitação de uma análise séria e bem feita dos desenhos, relegando-os ao anexo, nota de pé de página ou apresentados sem legendas.

Este texto se faz necessário porque, apesar da utilização dos desenhos cada vez mais frequente nas pesquisas com crianças, não aprendemos em nossa formação acadêmica - diferentemente da psicologia ${ }^{3}$ - a trabalhar com a técnica e há pouco material que nos oriente sobre os modos de proceder no uso dos desenhos em campo, tampouco sobre suas limitações. Esperamos que este artigo contribua para o debate em torno do uso do desenho, incentivando-o e, ao mesmo tempo, auxiliando-nos a nos apossar de forma concreta dos seus benefícios.

Além de problematizar a função do desenho nas pesquisas e nos textos antropológicos, este artigo reflete sobre a sua produção e as razões pelas quais sua confecção é uma importante ferramenta de pesquisa e aliada da pesquisadora que investiga crianças. Para isso precisamos estar dispostos a analisar não apenas os usos dos desenhos e sua inclusão nos trabalhos finais, mas o ato da produção em seus distintos contextos.

Nesse sentido, são duas as linhas argumentativas principais deste texto. A primeira é a de que a produção de desenhos deveria ser considerada como técnica legítima de pesquisa com crianças, desde que se reconheça a autonomia e as interpretações feitas pelas próprias crianças. A segunda é a de que é preciso, além de reconhecer a importância da técnica, descrever o processo de produção dos desenhos, deixando claras as condições em que se deu e revelando/reforçando sua utilização em conjunto com outras técnicas de pesquisa. Para além dessa dupla linha argumentativa, tecemos uma crítica à reduzida

2 Optamos por usar o gênero feminino porque, além da maioria das autoras serem mulheres, tomamos como fundamental o uso da língua para suscitar mudanças importantes.

3 Diferentemente dos psicólogos, os antropólogos não são treinados para inferir qualquer conclusão a partir de um desenho (Pires, 2007, p. 52). 
relevância que se dá aos desenhos - no que se refere a sua pouca inserção nos textos antropológicos.

Logo, neste artigo trabalhamos com um conjunto limitado de textos que serão analisados a partir dos seguintes aspectos: a) sua afirmação da importância dos desenhos para os achados da pesquisa; b) a descrição dos processos de produção dos desenhos - em que lugar, em que condições, com que material, em que espaço de tempo, etc.; e c) se foi feita a inserção dos desenhos no texto e de que maneira essa inserção se dá.

\section{Entendeu ou quer que eu desenhe?}

Uma vasta literatura pode ser encontrada sobre o uso dos desenhos em pesquisas de abordagens psicológicas, artísticas e na área da educação (Gibim; Müller, 2018; Gobbi, 2012; Goldberg; Frota, 2017). Em se tratando da antropologia a utilização dos desenhos infantis tem aparecido como técnica a se somar à observação participante em uso no empreendimento etnográfico (Cohn, 2006, 2008; Delgado; Müller, 2005; Faria; Dermatini; Prado, 2009; Faria; Finco, 2011; Ferreira, 2020; Mendonça, 2018; Müller; Carvalho, 2009; Müller; Dutra, 2018; Pimentel, 2020; Pires, 2007, 2009; Pires; Santos, 2019; Sanches, 2014; Santos, 2014; Sousa, 2017a; Tassinari, 2015, 2016; Toren, 1993, dentre outras pesquisadoras).

As antropólogas têm se utilizado da produção de desenhos como senha de acesso ao campo ou aos sujeitos da pesquisa - as crianças. Da mesma forma como os etnólogos utilizavam-se das crianças como senha de acesso aos adultos, em situações como as descritas por DaMatta (1978) e Seeger (1980). O uso dos desenhos como maneira de facilitar o estar entre as crianças tem se mostrado um recurso benéfico, utilizado inclusive pelas autoras (Pires, 2011; Sousa, $\left.2017 \mathrm{a}^{4}\right)$. No entanto, argumentamos que, para além do primeiro contato com as crianças buscando uma interação prazerosa, os desenhos também podem ser utilizados como um recurso de acesso às narrativas infantis.

4 Também utilizamos recursos como contação de histórias, brincadeiras livres e direcionadas, produção de fotografias, oficina de papel reciclado, dentre outros, a fim de facilitar nossos primeiros contatos. 
Enquanto nós, pesquisadoras de/com crianças, chegamos a elidir os desenhos ou relegá-los às últimas páginas dos nossos textos, as nossas interlocutoras, ao serem questionadas sobre a pesquisa, comumente lembrarão: "naquele tempo que a gente desenhava para ela [fazendo referência à pesquisadora]" (Sousa, 2015). Negligenciar os desenhos no produto final da pesquisa pode manifestar uma falta de apreço em relação ao esforço das crianças que se dedicaram com esmero para desenhar. Um modo de não reconhecer sua agência e sua autonomia nos modos de dizer de si mesmo (Sousa, 2018). ${ }^{5}$ Se o desenho ocupa um lugar importante na leitura que as crianças fazem da realização de uma pesquisa (Paula, 2012; Sousa, 2015), se é feito e apresentado às pesquisadoras como dádiva carinhosa (Ferreira, 2020; Mendonça, 2018; Santos, 2020) e nos conecta tão intimamente aos nossos interlocutores, como não levar a fundo a sua viabilidade na pesquisa antropológica?

Mas é preciso cautela, pois o uso do desenho apresenta vários riscos. Um deles está na constatação da importância da técnica durante a pesquisa, mas na sua ausência no decorrer do texto e na sua presença apenas em anexos. Quando colocados no meio do texto corre-se o risco de serem pouco explorados, sendo apresentados sem legendas ou com legendas precariamente ilustrativas. Acessamos as crianças através da confecção de desenhos e depois relegamos estes desenhos a um segundo plano, subestimando o potencial criativo da técnica, que não é explorada nas análises finais. O desenho infantil é um rico material ainda pouco valorizado.

A partir de uma leitura crítica ao material produzido na antropologia da criança recentemente, uma problematização dos usos atuais da técnica e a inclusão dos desenhos nos textos deve estar atenta aos seguintes riscos:

a) da redução de sua importância a mero artifício de interação entre pesquisador e interlocutores;

b) de uma suposta precária habilidade das antropólogas em lidar com desenhos;

c) e do uso limitado do potencial da técnica na produção de dados.

5 Embora agência e autonomia infantis sejam conceitos disputados no meio acadêmico, nos referimos aqui a ideia de que as crianças, ao desenharem, tem garantida a sua autonomia de escolha sobre o que desenhar, o que contribui para o exercício da sua agência. 
Por fim, argumentamos que os desenhos podem revelar coisas que não conseguiríamos compreender de outra maneira, manifestando sua importância como uma técnica que possibilita o estabelecimento de diálogos diretos e reentrantes com as crianças. Eles também proporcionam a interpretação infantil sobre suas obras e seus contextos, uma autorreflexão que só em casos de trabalho de campo bem sucedido pode ocorrer.

Por exemplo, Sousa (2014) demonstrou como não havia percebido a força da relação das crianças capuxu, sertão da Paraíba, com os animais, tampouco atentado para um sistema de nominação próprio dos bichos até que as crianças incluíssem os animais nos desenhos, além de nomeá-los nas obras quando nem mesmo os adultos apareciam nomeados. Foram também os desenhos das crianças capuxu que revelaram à autora a importância das estradas nas representações que as crianças tinham do Sítio Camponês, fugindo da dicotomia clássica dos estudos de campesinato que se limitava à casa e ao roçado.

Foi também o que aconteceu com Pires (2011) quando teve a surpresa de se deparar com uma árvore e uma lata de lixo ao pedir que as crianças desenhassem um mal-assombro. Esses desenhos foram primordiais para a análise que se seguiu ao sugerir que mal-assombros são complexos e variados aos olhos infantis, diferentemente do que se passa com os adultos, o que se transfigura no processo de introdução ao cristianismo (Pires, 2011).

Também Santos (2020) foi levada a compreender a presença primordial das TICs entre as crianças rurais e a relação de ensino/aprendizagem entre elas e os adultos - que mostravam dificuldade em usar as novas tecnologias - ao ter acesso a um desenho da tela de um celular exibindo a página do Facebook feito por uma criança, tendo esta relação intergeracional se tornado um dos fios condutores de sua pesquisa.

Goldberg e Frota (2017) afirmam privilegiar o desenho como via de acesso para uma pesquisa com crianças e não sobre elas. Defendem o desenho infantil como um porta-voz do seu universo, uma expressão singular e original das crianças, espaço em que representam o que sentem, pensam e querem dizer. É um recurso de fala da criança, especialmente da criança pequena, já que em geral expressa algo que não encontra caminho no discurso oral (Sarmento; Trevisan, 2017). Além disso, a inquietude típica da infância impossibilita quase sempre a realização de entrevistas, mas a confecção de desenhos associada às conversas informais pode ser útil às pesquisas com crianças menores. É nesse 
sentido que os desenhos têm sido utilizados com o objetivo de aprender com as crianças e com a realidade que as cerca através de uma linguagem essencialmente infantil - embora não exclusivamente infantil.

Alguns autores defendem o desenho infantil como artes visuais (Cunha, 2017; Lowenfeld, 1977). Para Cunha (2017, p. 80), "essas imagens não podem ser pensadas apenas como representações da realidade". Para Sarmento (2011, p. 30), o desenho das crianças necessita ser analisado segundo "uma gramática interpretativa das 'culturas da infância'”.6

Outras autoras entendem o desenho como representação da realidade (Gobbi, 2012; Grubits, 2003). Para Gobbi (2012), o desenho não é um recorte da realidade, mas uma representação do social informado por um tempo histórico e cultural do qual a criança participa. Segundo a pesquisadora (Gobbi, 2012, p. 155), "é um fragmento bom para pensar sobre diferentes questões teóricas e práticas referentes às dinâmicas sociais, envolvendo ou não as crianças, mas que podem seguramente partir delas".

Mas o desenho é capcioso. Um interessante exemplo disso é a sugestão de Pires (2011, p. 307):

Para a criança pequena, o desenho não representa um mal-assombro; é o mal-assombro. Uma vez, durante o trabalho de campo, uma criança desenhou um monstro-mal-assombro dizendo-me que já o tinha visto. Perguntei onde ela tinha visto aquele mal-assombro, ao que ela respondeu que ali não existia monstro. Indaguei: “E como foi que você já viu um?” E ela respondeu: "Eu desenhei!”

Nesse sentido, o desenho não é apenas uma representação, mas é ele mesmo criação. Ele traz à existência. Não significando ou sendo um símbolo de qualquer coisa, sendo, ele mesmo, a coisa criada, capaz de dar vida a algo que até então não existia. É preciso entender que mesmo interlocutores adultos produzem leituras de mundo à medida que falam. Ora, se os adultos constroem sentidos à medida que narram as experiências através da fala, as crianças também constroem sentidos à medida que desenham. Desenhar, nesse caso, é contar algo

6 Culturas da infância referem-se à capacidade da atuação das crianças como atores sociais críticos que desenvolvem modos de significação e ação próprios, que se distinguem dos modos de ação e significação dos adultos (Sarmento, 2004). 
que pode, inclusive, não existir até que o desenho fique pronto. São os desenhos formas de exploração do real e processos constitutivos de sua compreensão:

Tudo se passa como se a criança procure no seu desenho não propriamente representar um real exterior ao desenho, mas, desenhando-o, o inscreva como o real da representação, válido em si próprio e interpretável no quadro da polissemia tolerada pelos códigos em que ele foi desenhado. (Sarmento, 2011, p. 39).

Aludimos, apenas, que os desenhos na pesquisa antropológica com crianças não têm o intuito de discutir fases de desenvolvimento ou informar um tratamento clínico, como o faz a psicologia, nem tampouco o valor ou as impressões artísticas de cada desenho, sendo o desenho, para a pesquisa antropológica, um modo de acessar as percepções dos sujeitos.

\section{As contribuições de Margareth Mead e Christina Toren}

Os desenhos já são utilizados na pesquisa antropológica há tempos, como exemplo temos a pesquisa de Mead e Bateson em Bali, na qual teriam coletado mais de mil desenhos feitos em sua maioria por adultos. Preocupada com a distinção entre o inato e o adquirido, Mead $(1963,1985)$ realizou pesquisas entre as crianças manu revelando-as voltadas à exatidão e ao detalhe preciso, ao contrário da visão que se tinha da infância universalizada pela sociedade norte-americana, como imaginativa e fantasiosa. Para tanto, Mead se utilizou da observação participante somada à análise dos desenhos produzidos pelas crianças, fornecendo os meios para o desenho sem predeterminar o que desenhar. Conforme Mead (1985, p. 211, tradução nossa):

Jamais tinham tido um lápis em mãos. Comecei dando papel e lápis aos meninos de 14 anos, sugerindo que desenhassem e deixando-os livres para eleger o tema. No dia seguinte dei instrumentos de desenho para o grupo que se seguia imediatamente a este em idade e assim continuamos até que foram recrutados a essa tarefa os pequenos de três anos. Compreendi que esse era o sistema mais aproximado ao ensino normal que eu podia aplicar, evitando que os adultos desenhassem, pois isso teria modificado os termos da investigação. 
Recolhidos os desenhos e catalogados, com informações sobre o sexo e a idade das crianças, Mead os analisa enquanto tece comentários sobre eles. Os desenhos das crianças manu revelavam o gosto pelo exato e à capacidade mnemônica sem confirmar a universalidade da imaginação fantasiosa infantil, demonstrando a dicotomia entre inato e adquirido (natureza versus nurture). Essa conclusão se dá a partir da análise dos desenhos aliada à observação de seu cotidiano.

Toren (1993) dedica-se ao estudo de crianças fijianas e se utiliza dos desenhos buscando entender os sentidos que as crianças de Fiji dão ao mundo. Segundo a autora a hierarquia é um tema central em Fiji, e as relações devem ser vistas como manifestações diversas desse tema. Logo, os desenhos têm por tema a hierarquia e sua inserção no espaço, já que para Toren os desenhos seriam instrumentos de pesquisa capazes de capturar a percepção de hierarquia das crianças. Logo após desenhar, as crianças faziam um relato sobre o desenho. A pesquisadora acreditava que as percepções sobre hierarquia das crianças seriam reveladas a partir da disposição espacial das pessoas nos desenhos, uma vez que a hierarquia em Fiji surge da composição de ranking, senioridade e gênero distribuindo as pessoas no espaço, de acordo com um eixo acima/abaixo. Toren afirma que só teve acesso a essa compreensão porque buscou entender a percepção das crianças sobre essas situações, sobre a hierarquia e as posições relativas, sobre gênero e senioridade: "esse achado me permitiu desafiar a teoria de que a hierarquia fijiana estava baseada apenas em uma distinção de rank entre chefes e o povo" (Toren, 1993, p. 463, tradução nossa). Assim, a autora enfatiza a importância de se considerar as crianças nas pesquisas sob pena de se ter uma visão incompleta da realidade.

Sua análise dos desenhos parte desses temas - a ocupação das posições; percepções sobre gênero e sua relação com a hierarquia; a percepção das crianças das diferenças em determinados contextos e reuniões; e as idades e gênero das crianças. Esses dados são complementados por entrevistas com as crianças sobre desenhos.

Não faz sentido descartar as ideias das crianças como imaturas, ou afirmar que elas não entendem o que de fato está acontecendo. As crianças têm que viver suas vidas a partir dessa compreensão, assim como os adultos o fazem; suas ideias estão baseadas em suas experiências e portanto são igualmente válidas. $O$ desafio para o antropólogo é analisar o processo que torna possível que as crianças 
levem a vida efetivamente a partir de ideias que são uma inversão daquelas abraçadas por seus pais e outros adultos. (Toren, 1993, p. 463, tradução nossa).

Cohn (2006, p. 7, grifo da autora) analisa a descoberta de Toren:

Ela afirma o valor para toda análise antropológica, e não apenas a que se dedica às crianças, de perceber o ponto de vista das crianças, que se torna revelador do mundo tal como vivido por aqueles que são objeto das reflexões antropológicas. Se a inversão de sentido é tão eficaz para informar o comportamento e as ações quanto o sentido atribuído pelos adultos, é porque ela é tão verdadeira quanto, e portanto expressa tão bem quanto o mundo concebido e vivido. Desse modo, ouvir as crianças é completar uma percepção sobre o mundo que ficaria efetivamente incompleta se só se ouvisse os adultos.

Recentemente, ao ser indagada sobre os usos dos desenhos em suas pesquisas, Toren descreve sua experiência na entrevista concedida a Aline Regitano e publicada na revista Proa, da Unicamp:

Eu não fui a criadora dessa ideia brilhante. Mas eu acho que usei os desenhos de uma forma diferente de qualquer outra pessoa, porque eu estava realmente interessada em descobrir o que as crianças sabem sobre o mundo em que vivem e eu não estava "testando" elas. Eu não estava tentando descobrir sobre o desenvolvimento de sua perspectiva, digamos. Eu não tinha noção de que tipo de fim de desenvolvimento elas iriam chegar, eu estava usando os desenhos absolutamente para mostrar quais ideias as crianças tinham sobre o jeito que as coisas são. (Toren, 2019, p. 296).

Toren aponta as vantagens de se utilizar a técnica dos desenhos como forma de deixar as crianças à vontade, sem que elas se preocupem em fornecer as respostas certas aos adultos.

As crianças pequenas eram bastante cautelosas comigo, não apenas porque eu era uma pessoa de aparência incomum em seu grupo, mas porque elas eram cautelosas com os adultos em geral. E elas tinham certeza de que havia uma resposta certa, entende o que eu digo? Não faz sentido perguntar coisas para 
as crianças, a menos que você esteja fazendo isso de maneira muito informal, e ainda assim elas podem ficar um pouco preocupadas. Os desenhos pareciam uma maneira de fazer as crianças me contarem coisas, porque elas se divertiam fazendo isso, eu sabia que elas adoravam fazer isso, sabe, eu dei um papel legal e um lápis com borracha na ponta. Se você quer que uma criança fale é muito mais fácil ser capaz de dizer "puxa, esse é um ótimo desenho, quem é esse? Me fale sobre isso". E, naturalmente, elas vão contar tudo sobre todas as coisas para você. (Toren, 2019, p. 296).

A autora defende que não devemos fazer interpretações dos desenhos por eles mesmos, mas devemos usá-los como meios para acessar as interlocutoras e suas narrativas. Além de um caminho até as crianças os desenhos podem ser, para nós, antropólogas, um caminho até os pontos de vista das crianças, suas representações e suas leituras de mundo. Dessa forma, Toren assume uma postura ativa no processo de realização dos desenhos, ao perguntar para as crianças, por exemplo: “Quem são essas pessoas? Há mulheres aí? Onde elas estão sentadas? Por favor, me mostre. E quanto aos homens - há homens aí? Por favor, me mostre. Onde eles estão sentados?..." (Toren, 1990, p. 198, tradução nossa). Logo, a pesquisadora levava as próprias crianças a compartilharem suas ideias transpostas para o papel em uma narrativa.

Ao ser questionada sobre como definir os limites de expressão das imagens e se haveria uma hierarquia sobre a escrita e a fala em relação às imagens, Toren (2019) afirma que as imagens têm limitações tanto quanto a fala na pesquisa antropológica. A autora defende que o que importa é a análise etnográfica, que pode ser feita de um filme ou desenho. O que define, portanto, o caráter etnográfico de um trabalho é a natureza de sua análise.

\section{O processo de produção dos desenhos e sua associação com outras técnicas na pesquisa com crianças}

Tratar as crianças como sujeitos e não como objetos de pesquisa é a ideia-base da antropologia da criança (Christensen; James, 2008), que volta a pesquisa às vozes das crianças. Nesse sentido, as pesquisas com crianças devem considerar o processo de produção de desenhos a ser acompanhado por diálogos, e sua análise 
deve ser feita a partir do que foi dito pelas crianças e os significados atribuídos por elas mesmas. "Os desenhos úteis para a pesquisa antropológica são, sem dúvida, aqueles nos quais as crianças se esmeraram nos comentários" (Pires, 2007, p. 52).

Na pesquisa de Pires (2007) foram feitos três tipos de desenhos: 1) livres; 2) temáticos; e 3) temáticos controlados. São chamados de desenho livre os desenhos sem tema definido a priori, onde as crianças decidem por elas mesmas, às vezes individualmente, às vezes coletivamente, o que desenham.

Muitas vezes, elas mesmas tomavam a iniciativa de pedir para desenhar; outras vezes, eu sugeria. Este tipo de desenho é interessante principalmente em um primeiro momento da pesquisa porque, a partir dele, pode-se melhor definir os temas que devem ser aprofundados. (Pires, 2007, p. 237).

Ainda que chamemos a técnica de desenhos de espontânea ou livre, concordamos com Mèredieu (2017) que em primeiro lugar somos nós, os adultos, que oferecemos os instrumentos para as crianças desenharem e decidimos a importância dos desenhos para a nossa pesquisa, se estes são dignos de serem analisados e incluídos nos trabalhos finais. Mèredieu (2017) também afirma a inegável influência do universo adulto sobre o infantil, de modo que não existiriam desenhos infantis livres de qualquer influência. Por isso, reforçamos a importância de atentarmos para o processo de produção dos desenhos e para a influência externa às crianças que podem orientá-las mesmo quando eles nos parecem absolutamente livres.

Sousa (2017a), analisando a produção da pessoa capuxu através da fabricação dos corpos das crianças, viveu uma interessante experiência ao solicitar às crianças que desenhassem algo para ela, deixando-os desenhar "livremente". Qual foi a surpresa quando se deu conta de que todos os desenhos apresentavam o Sítio Santana-Queimadas onde vivem os Capuxu. Curiosa com a escolha unânime das crianças, Sousa entendeu mais tarde que tal feito era produto do modo como os adultos do sítio se referiam à pesquisadora e a apresentavam para as crianças, sempre pensando em seus interesses de pesquisa, "ela faz uma pesquisa sobre o Sítio" ou "a menina que pesquisa o Sítio". Assim, as crianças entenderam que poderiam contribuir para a pesquisa desenhando o sítio.

Se, em um primeiro momento, Sousa (2017a) avaliou que aquele conjunto de desenhos lhe parecia inútil, aos poucos foi se dando conta da quantidade de 
elementos presentes nos desenhos "do sítio" que revelam as singularidades da organização social capuxu. Assim, a autora conta como os desenhos das crianças lhe orientaram por importantes aspectos da organização social capuxu para os quais não havia atentado, dentre eles o sistema de nominação dos bichos e a agência infantil presente nele (Sousa, 2014). No entanto, a autora não detalhou o processo de produção dos desenhos para além da informação de que, apesar do seu objetivo não estar relacionado com aprendizagem escolar, os desenhos foram realizados em sala de aula.

Outra coisa a se considerar no processo de confecção dos desenhos é que, em algumas circunstâncias, as crianças não se apegam à sua obra, especialmente as crianças pequenas. Uma vez concluída a torna descartável, lhe é efêmera. As maiores podem presentear pesquisadoras (Ferreira, 2020; Mendonça, 2018; Santos, 2020), pais, amigos com as suas obras, mas as menores as descartam no lugar mesmo em que as fizeram, passando a uma nova atividade. O que conta para a criança parece ser o processo. Elas se divertem durante o processo, talvez mais do que com o produto final. Ainda assim, tendemos a omitir o processo de criação dos desenhos nos textos.

Manter conversas com as crianças durante e após a produção dos desenhos sobre o que se desenhou é essencial, devendo as pesquisadoras recorrerem à oralidade sempre que possível (Gobbi, 2012; Pires, 2007; Sarmento; Trevisan, 2017; Toren, 1993, 2019), embora seja possível que os significados atribuídos pela criança ao mesmo desenho variem de um dia para o outro, o que não constitui um problema.

James, Jenks e Prout (1998, p. 189, tradução nossa) concordam que a eficácia da técnica do desenho é potencializada na medida em que eles são motivos de discussões posteriores:

Conversar com as crianças sobre os significados que elas atribuem para seus desenhos ou pedir a elas que escrevam uma história permite que as crianças se engajem mais produtivamente com as nossas questões de pesquisa, usando os talentos que elas possuem.

Além disso, o desenho mostra-se uma técnica adequada para trabalhar com as crianças, dentre outras coisas, porque desenhar é um ato que não requer nenhuma habilidade especial na nossa sociedade, uma vez que constantemente 
as crianças desenham por lazer. Além disso, "o desenho está menos sujeito à crítica, se comparado ao texto escrito (em relação, por exemplo, à correção gramatical e ortográfica) e, portanto, menos associado às atividades desenvolvidas no ambiente escolar" (Pires, 2011, p. 52-53).

Há que se considerar ainda que à medida que crescem, as crianças tendem a se demorar mais desenhando, deixando seu produto caprichado. $O$ fato é que quanto mais legível o desenho, mais influenciado pela escola e os adultos ele foi, embora, em termos práticos, mais uteis à pesquisa antropológica se tornem. Se forem duradouros os anos de pesquisa, poderá se obter desenhos com percepções diferenciadas ou mais amadurecidas da mesma criança, no início e no final dos anos da pesquisa. Esse amadurecimento e diferença na leitura de mundo também ocorre aos adultos ao longo da vida, mas de maneira mais lenta. No caso das crianças esse processo se torna mais acelerado, podendo tornar-se perceptível em pesquisas realizadas ao longo de dois anos, por exemplo (Mèredieu, 2017).

Na busca por ouvir a voz das crianças é preciso atentar para mais do que a voz, pois há modos de produzir discursos que são distintos da fala, e precisam ser considerados por quem pesquisa com crianças pequenas.

O desenho infantil insere-se entre as mais importantes formas de expressão simbólica das crianças. Desde logo, porque o desenho precede a comunicação escrita (na verdade, precede mesmo a comunicação oral, dado que os bebês rabiscam antes ainda de articularem as primeiras palavras). Depois, porque o desenho infantil, não sendo apenas a representação de uma realidade que lhe é exterior, transporta, no gesto que o inscreve, formas infantis de apreensão do mundo - no duplo sentido que esta expressão permite de "incorporação" pela criança da realidade externa e de "aprisionamento" do mundo pelo ato de inscrição - articuladas com as diferentes fases etárias e a diversidade cultural. Nesse sentido, o desenho infantil comunica, e fá-lo dado que as imagens são evocativas e referenciais de modo distinto e para além do que a linguagem verbal pode fazer. (Sarmento, 2011, p. 28-29).

Pois, se as crianças têm modos próprios de dizer de si e do mundo que as cerca, e esses modos não estão circunscritos ao universo da linguagem apenas, precisamos estar atentas às formas pelas quais as crianças escolhem falar, ou seja, a maneira como falam para além do conteúdo - sobre o que falam. 
O lugar e as circunstâncias em que os desenhos são produzidos devem também ser considerados. Constatamos que desenhos feitos em salas de aula de escolas (Bordin; Bussoletti, 2014; Müller; Dutra, 2018), consultórios psicológicos (Mueller, 2019) ou até mesmo prisões (Ferreira, 2020) são permeados por uma preocupação das crianças com o certo e o errado típico das avaliações escolares. Acreditamos que é preciso desvencilhar o processo de elaboração de desenhos em pesquisas antropológicas da sala de aula, sempre que possível, para dissipar a associação frequente dos desenhos produzidos com fins de pesquisa e as tarefas escolares. Ou seja, seria interessante que sempre que a pesquisa ocorresse em outros âmbitos que não o da escola, os desenhos fossem produzidos em outros espaços por onde ocorre a pesquisa, não condicionando a produção de desenhos às salas de aula da escola nem legitimando a associação feitas pelas crianças de que esses desenhos são obrigatórios como as demais tarefas escolares.?

Cohn (2008) fez uma observação interessante da diferença de desenhos feitos em sala de aula para professores não indígenas e os espontâneos elaborados a pedido da antropóloga. Os primeiros solicitaram desenhos com o tema "coisas tradicionais de sua própria cultura":

Esses desenhos guardam algumas particularidades frente ao que denominei "desenhos espontâneos", de tema livre, feitos fora da escola, para mim. Nestes, poucas vezes se criam situações, e os elementos são organizados pelo papel ao girarem-no para acrescentar novos elementos (o desenho escolar segue uma orientação vertical, respeitando o formato do papel na exata forma da leitura). Os temas e elementos representados mudam também: dentre os preferidos, animais, como a onça, o tatu, peixes; o campo de futebol com seus jogadores e a bola; a aldeia em seu formato circular; caminhões e tratores puxando a madeira; barcos a motor; aviões; e uma casa em que pessoas são vistas pelos cômodos banhando em seus chuveiros... Para os professores, nada de animais: quando seres animados são representados, são pessoas, em seus afazeres cotidianos, dançando no ritual, pescando, caçando. Para os professores, também, nada de objetos de brancos - que no entanto são largamente desenhados quando se lhes

7 Em relação a desenhos produzidos em escolas, ver Bordin e Bussoletti (2014) e Müller e Dutra (2018). 
dá a liberdade de desenhar qualquer coisa que lhe cative a atenção e o interesse. (Cohn, 2008, p. 10).

Sousa (2017a) na intenção de dar conta das representações das crianças que moram ao longo do corredor da Estrada de Ferro Carajás sobre a empresa Vale, a linha de trem e o próprio trem - que cruza seus municípios, seus caminhos e suas vidas - optou por solicitar às crianças que fizessem desenhos nas estações e nos vagões do trem durante as viagens, o que tornou os desenhos românticos, divertidos, sem refletir a pobreza e os impactos causados pelo trem e pela própria EFC, objetivos da pesquisa. Nesse caso, as crianças foram orientadas a desenhar o trem, a linha de ferro, as estações e o que mais desejassem (Sousa, 2017a). Isso nos leva a refletir sobre como os lugares onde os desenhos são feitos e as condições, de maneira geral, podem ser determinantes dos desenhos que obtemos das crianças.

Antropólogas que investigam a infância têm defendido que não são necessários métodos de pesquisa específicos para se pesquisar com crianças porque “o estudo das crianças não requer técnicas especiais, mas, simplesmente, uma aplicação rigorosa de exigência metodológica geral" (Prout, 1999 apud Christensen; James, 2008, p. X, tradução nossa). Se não precisamos criar métodos para dar conta do ponto de vista das crianças, concordamos que alguns métodos e técnicas já tradicionais da antropologia são especialmente eficazes para trabalhar com elas.

Pesquisas contemporâneas têm apresentado um esforço no processo de escuta às crianças por meio da utilização de diferentes estratégias metodológicas (Delgado; Müller, 2005; Müller; Dutra, 2018; Pires, 2007, 2009; Pires; Santos, 2019; Sousa, 2017a, 2019; Tassinari, 2015; Toren, 1993). Müller afirma que a antropologia da criança demanda uma abordagem diversificada, articulando observação e outras técnicas de pesquisa (cf. Corsaro, 2007).

A importância dos Odesenhos como técnica de pesquisa que pode ser aliada a entrevistas e conversas informais é comentada por Horn (2013) ao ganhar das crianças os desenhos como modo de fazê-la lembrar aquilo que lhe fora dito.

[...] propus uma conversa em grupos - geralmente grupos de quatro. Até o momento das entrevistas, percebi que as crianças daquele grupo conversavam bastante sobre si e sobre suas vidas enquanto desenhavam (desenhos diversos 
- livres ou dirigidos pela educadora). Assim, optei por propor um desenho sobre o que mais gostavam na escola e, a partir disso, lancei algumas questões, deixando que elas conversassem sobre as coisas da escola enquanto desenhavam. Ao final da conversa, a maioria deixou o desenho comigo como presente, lembrança, algo para não ficar esquecido em relação àquele momento. Uma criança disse: "Fica com o meu desenho, assim tu te lembra do que eu te contei." (Horn, 2013, p. 12).

A reflexão de Horn também enfatiza o que Pires (2011) e Toren (1993) afirmam no sentido de que são favoráveis ao uso do desenho conjugado com a técnica da observação participante, dentre outras razões, por incluir os adultos. Pires (2011) aponta ainda que a antropóloga que conhece o seu campo de estudo saberá distinguir um desenho que faz sentido num conjunto de dados. Gibim e Müller (2018, p. 78) afirmam que "dentre um leque de possibilidades, o desenho tem potencial de captar a forma expressiva por meio da qual as crianças representam o mundo".

Silva e Melo (2009) realizaram pesquisa na cidade de Timbiras (MA) e de Guariba (SP) sobre a migração das famílias para a região canavieira de Ribeirão Preto (SP). Uma das indagações da investigação dizia respeito ao trabalho e à vida das mulheres que ficam separadas de seus maridos ou filhos durante nove meses ao ano. As autoras reuniram os desenhos de crianças sobre a representação da região de Ribeirão Preto e a família de pertencimento, com o intuito de captar "as vozes das crianças envolvidas neste processo migratório". Conforme as autoras:

Ouvir as vozes das crianças, geralmente, alijadas da análise sociológica, em geral adultocêntrica, é um desafio para a compreensão da realidade social. Consideramos as crianças como sujeitos sociais, que possuem outras formas de expressão, sendo o desenho, uma delas. Acreditamos assim que algumas lições podem ser tiradas destas vozes. (Silva; Melo, 2009, p. 43).

Silva e Melo (2009) discorrem sobre o processo de produção dos desenhos das crianças. Elas tratam da associação entre vários métodos de pesquisa e dos modos de interpretar os desenhos a partir do que chamam de conteúdo manifesto e latente. As autoras refletem:

Portanto, a investigação precisa recorrer a outras ferramentas a fim de captar além do visível, o invisível. Os desenhos das crianças permitem a revelação 
destes elementos visíveis e escondidos. Eles traduzem o mundo imaginado, desejado e também aquele que é real, embora não desejado. Revelam, portanto, a contradição entre real e irreal, entre partir e ficar, entre "ir quando inteirar idade" e ficar, "não precisar trabalhar no corte de cana, jamais" (segundo o desejo de seus pais). Ao desenhar, a criança revelou às pesquisadoras seus mundos real e imaginado, fruto de suas curtas existências, porém ricas em significados. (Silva; Melo, 2009, p. 50).

Monteiro (2015) pesquisou as concepções de infância dos ciganos calon do Vale do Mamanguape, na Paraíba. Para isso trabalhou com o método etnográfico, a observação participante, o grupo focal, os desenhos temáticos infantis e entrevistas com roteiros semiestruturados. As crianças calon desenhavam e explicavam para Monteiro os seus desenhos. A autora apresentou um conjunto de 11 desenhos colocados no corpus do texto, com rápidas legendas explicativas, uma letra identificando a criança e sua idade. Confeccionados a partir dos temas "coisas de cigano" e "calon versus juron" (não cigano), as crianças apresentaram elementos para entender a etnicidade calon em contrapartida à dos juron.

Tassinari (2016) elaborou uma etnografia das casas de farinha galibi-marworno enquanto espaços de aprendizagem intergeracional, infância e cognição. Para tanto, a autora fez a descrição de atividades na produção de farinha, a análise de desenhos infantis e entrevistas com adultos. Assim, a pesquisadora elege as categorias aprendizagem, observação, imitação, atenção e corporalidade como razões que transformam as casas de farinha em uma espécie de escola. Nesse artigo Tassinari (2016) apresenta um conjunto de 37 desenhos de três hãs distintos (família extensa matrilocal) com curtas legendas explicativas, revelando o caminho que percorreu junto aos desenhos para chegar às conclusões.

Na importante análise comparativa de ensino e aprendizagem entre as famílias agrícolas de Turvo no Paraná e as famílias indígenas galibi-marworno no Amapá, Tassinari (2015) também se utilizou de desenhos ao analisar a participação das crianças nas atividades produtivas familiares através das categorias aprendizagem, experiência, corporalidade, imitação e responsabilidade. Através de quatro desenhos, dois das famílias indígenas e dois das famílias agrícolas, a autora ilustra seu argumento de que as crianças aprendem através da experiência nesses distintos contextos. Os desenhos são dispostos sem a identificação da criança ou sua idade, mostrando sua força para o argumento da autora. 
Müller e Dutra (2018) tratam de experiências urbanas de crianças durante os mais variados percursos realizados cotidianamente com ou sem acompanhantes em Brasília e Florianópolis. Nas duas cidades, as pesquisadoras consideraram o desenho como um recurso de comunicação por dar à criança a possibilidade de se expressar por meio de uma linguagem narrativa e simbólica, e por poder ser usado como um orientador para uma conversa com a criança. Dez desenhos estão expostos ao longo do artigo sendo analisados criteriosamente.

\section{O lugar dos desenhos nos textos antropológicos}

Ao longo deste artigo temos defendido que o uso de desenhos aceita, na antropologia, ser associado a outras técnicas de pesquisa, tendo destaque entre essas associações aquela que se faz à observação direta. Temos dito também que uma importante estratégia para utilização dos desenhos é solicitar às crianças que narrem sobre eles, digam de suas intenções, apresentem os elementos de seus produtos nas chamadas conversas informais ou pequenas entrevistas sobre suas produções, a depender da idade da criança. ${ }^{8}$

Considerando o fato de que a confecção de desenhos tem despontado como importante técnica de pesquisa, passamos a nos perguntar qual o lugar dos desenhos nos trabalhos finais na antropologia. Ora, o texto antropológico é mais importante do que a técnica? Por que tantas pesquisadoras se utilizam da técnica chegando a mencioná-la em seus capítulos metodológicos como uma senha privilegiada de acesso aos sujeitos, mas não expõem os desenhos nesses trabalhos?

Quanto aos modos de inseri-los nos trabalhos finais há, em geral, dois modos: a) no meio do texto, representando o que acabara de ser revelado pelo autor; ou b) em parte anexa, fazendo menção a eles - comumente através de um: vide Anexo I ou vide Figura 58 no Anexo II - quando o que fora dito no texto está relacionado ao que o desenho representa. O que essa inserção marginal dos desenhos nos textos nos informa?

8 As autoras que trabalham com desenhos deveriam sempre mencionar a idade das crianças. Toren (1993) menciona, além da idade, os meses de vida de cada criança. 
É muito comum observamos trabalhos que se delonguem na defesa do uso da técnica e até mesmo em como se deu todo o processo, sem que esses desenhos sejam inseridos no trabalho final. Assim, os desenhos desaparecem da mesma forma que as crianças desapareciam nos mais diversos relatos etnográficos da etnologia indígena: elas eram as primeiras a receberem as pesquisadoras, serviam-lhes de guias, levavam recados, faziam-lhes companhia, mas essa presença se tornava mera nota de pé de página. E agora, quando finalmente estamos nos dedicando às crianças e olhando para elas enquanto sujeitos legítimos de pesquisa, aniquilamos os seus desenhos.

O desenho encapsula a possibilidade de ouvir as crianças, mais do que dar a elas voz, na medida em que somos nós adultos que não temos ouvido as crianças, enquanto elas sempre falaram. A questão trazida por Spivak (2010) pode ser pensada também para as crianças - podem as crianças falar? De um ponto de vista adultocêntrico e colonizador, as crianças não passam de subalternos a quem não é dado o direito de fala. De outro lado, o argumento provoca uma reação em torno da escuta das crianças a partir de preceitos não infantis.

Monteiro e Goldfarb (2017) apresentam uma análise do sentido de ser criança cigana na Paraíba, e reforçam a utilização da observação participante, das entrevistas com os adultos e grupos focais com adultos e crianças e desenhos infantis. Ao longo do artigo os resultados são apresentados, mas desenho algum é inserido. Também não se exploram as condições de elaboração dos desenhos e como eles orientaram as pesquisadoras até os resultados, enquanto parte das entrevistas (a fala, propriamente) são descritas no texto.

Ao realizar uma reflexão metodológica sobre representações infantis de crianças que residem ou trafegam nas faixas de servidão sob as linhas de transmissão da Eletronorte na Ilha de São Luís, Sousa (2019) utiliza os desenhos infantis como importante ferramenta de pesquisa, mas eles não aparecem no artigo. Os resultados da pesquisa aparecem a partir de fragmentos inteiros reproduzidos das conversas com as crianças, mas a autora não insere os desenhos.

Por outro lado, quando se opta por apresentar os desenhos das crianças, eles vêm nas páginas finais do trabalho, marginalizados em itens complementares como anexos ou apêndices, juntos aos formulários burocráticos de conselhos de ética, de Termos de Consentimentos Livre e Esclarecido, de roteiros de entrevistas estruturadas ou semiestruturadas ou de roteiros de observação (Pires, 2011; Santos, 2014). 
Quando são trazidos para o trabalho, às vezes distribuídos ao longo do corpus do texto, lugar de destaque, os desenhos se apresentam em pequena escala, reduzidos a tamanhos que os tornam quase incompreensíveis, elaborados com lápis grafite, o que os torna ilegíveis, muitas vezes sem a assinatura ou a idade das crianças - quando se expõem os desenhos, se omitem seus autores ${ }^{9}$-, sendo estas informações, quando trazidas, colocadas nas legendas-padrão e em listas de figuras no prenúncio do trabalho. Curioso, então, que as listas intermináveis de desenhos que aparecerão nos trabalhos estejam colocadas em suas primeiras páginas, e eles apareçam apenas no final. Algumas dessas relações se referem a esses desenhos, não debalde, através da nomenclatura ilustrações. Muitas vezes é exatamente essa a função que os desenhos assumem nos trabalhos finais. Eles ilustram os argumentos do autor, reforçam suas teses, simbolizam suas alegações. Sendo meramente ilustrativos, não são explorados em seus sentidos diversos ou naquilo que deles disseram seus autores.

Nas reflexões metodológicas, as autoras têm dificuldade em tratar com esmero do processo de criação dos desenhos - em que circunstâncias, com que material, com que nível de interesse pelas crianças. Se foram livres ou temáticos, com ou sem orientação. Se foram individuais ou em pares, e se as crianças puderam optar por fazê-los ou não. Se no âmbito da escola, perguntamo-nos se ficou claro que os desenhos elaborados para a pesquisadora não eram uma atividade curricular, escolar, passível de avaliação e nota, ou algo pelo qual a criança seria penalizada ou chamada à atenção pela professora caso não fizesse.

Se as crianças puderam fazê-los pelo chão - como em geral gostam - deitadas (Pimentel, 2020) ou se tiveram de fazê-los sentadas em suas carteiras, com tempo determinado, material limitado e sob a supervisão da pesquisadora e/ou da professora (Bordin; Bussoletti, 2014). Se em salas de consultórios psicológicos - como em Mueller (2019) - ou em estações ou vagões de trem (Sousa, 2017b). Se escolheram as próprias cores, se cores e papel foram preestabelecidos, se desejavam ou não desenhar naquela situação.

9 Reconhecemos a complexidade que envolve a ética na pesquisa antropológica e, ainda mais, em relação às crianças. Todavia, estamos questionando os meandros do reconhecimento da autoria de um produto individual. 
Todo processo desaparece da análise etnográfica, quando as antropólogas optam por se demorar destacando o fato de o desenho aproximar crianças, seduzi-las para perto do pesquisador, numa espécie de moeda de troca: a matéria-prima das crianças, conversas informais, hipnotizadas pelo processo lúdico de desenhar e pintar; a matéria-prima do pesquisador - papel e lápis de cor.

No que se refere à análise dos desenhos, em alguns casos a antropóloga se esforça por interpretá-los, sem nem ouvir as crianças. Assim, termina por construir textos explicativos e tenta, através de suas interpretações, atribuir sentidos aos desenhos, alcançar percepções e representações sobre um determinado tema, fio condutor do seu trabalho. Desse modo, os desenhos das crianças acabam sendo analisados a partir de uma referência a uma perspectiva adulta, como fez Sanches (2014).

Os usos que fazemos de tais desenhos, os lugares que escolhemos para expô-los, as escalas em que são colocados, as cores e a qualidade da impressão e as interpretações que elaboramos muitas vezes não são aprovadas pelos seus autores antes de irem ao texto final. Muitas vezes, as crianças se surpreendem com suas obras em capas e contracapas, em escala menor ou maior, sem o colorido que lhe fora atribuído, mas transformados em preto e branco ou escalas de cinza, expostos sem que apareça sua assinatura ou idade, especialmente nos produtos cuja anonimato das crianças é assegurado pelas avaliações rigorosas dos conselhos de ética.

Tudo isso fere o discurso de que se tem valido a antropologia da criança, de que é preciso reconhecer nas crianças sua agência (Lima; Sousa, 2020; Sousa, 2018), que elas são capazes de decidir se querem ou não participar das nossas pesquisas, se decidem ter seus nomes e rostos revelados ou não, e como querem que apareçam as suas produções - a exemplo dos desenhos. Fere também o esforço das crianças de contribuir para as nossas pesquisas, seja através de entrevistas, conversas informais ou desenhando.

Se vamos atribuir ao desenho a legitimidade de uma técnica a ser utilizada nas etnografias com crianças, não devemos criar hierarquias que a torne menor do que entrevistas, questionários ou conversas informais. Precisamos legitimá-la enquanto tal. Reforçar a sua importância, discorrer sobre as condições de produção dos desenhos nos capítulos metodológicos como o fazemos a respeito de quaisquer outras técnicas e parar de utilizar os desenhos apenas como moeda de troca em negociações entre pesquisadoras e crianças. Quando 
os desenhos desaparecem dos textos, quem perde é a antropologia, por não ter à disposição os desenhos primorosos de crianças - valiosa matéria-prima -, que serão descartados ou arquivados sem uso adequado.

Um bom exemplo é descrito por Paula (2012), que analisou os usos sociais que as crianças faziam da mídia na vida cotidiana em uma escola de Belo Horizonte. Para isso, Paula realizou entrevistas, solicitou que as crianças fizessem desenhos e retirou fotografias das várias etapas. Ao descrever sobre o processo de negociação da produção do texto final da sua pesquisa de mestrado com as crianças participantes - de cinco a sete anos - a autora conta que levou às crianças o resultado: sua dissertação encadernada. A autora narra a curiosidade das crianças para verem o que chamavam de "livro da pesquisa", mas foi só iniciar as apresentações que as reações das crianças foram de reprovação. Vejamos um dos diálogos que se estabelece entre a autora, denominada no fragmento de Esperança, e algumas das crianças desapontadas:

Yuri: Você tem que aumentar o desenho, eu não desenhei assim.

Esperança: Assim como?

Yuri: Pequeno. - Tá muito pequeno. Tem que aumentar.

Esperança: Mas eu tive que colocar pequeno para poder escrever o que aprendi com os desenhos.

Yuri: A gente deixa você tirar o escrito.

(Paula, 2012, p. 233).

Esse fragmento reflete sobre a importância que as crianças dão ao desenho, enquanto a pesquisadora privilegiava as explicações escritas sobre eles. Muitas vezes os desenhos elaborados ao longo de nossas pesquisas se tornam a maior referência a ela pelas crianças, a memória mais bem elaborada e o sentimento instaurado nos nossos interlocutores de sua maior contribuição. Argumentamos aqui que, se nos interessamos por tornar as crianças coautoras e cúmplices de nossos trabalhos, e desejamos reconhecer e fazer reconhecer sua participação nas pesquisas e nos textos etnográficos, devemos considerar o desenho como um dos instrumentos que permite a maior participação das crianças, tirando-as muitas vezes da situação de meros sujeitos/objetos, passivos e passíveis de observação, para se sentirem úteis e contribuindo para a pesquisa. Ansiosas, elas esperam ver em nossos trabalhos aquela contribuição que lhes parece 
mais substancial, uma vez que crianças não costumam ler dissertações, teses ou artigos em antropologia. Tirar delas esse esforço nos parece um equívoco.

Sanches (2014) analisando a relação entre criança e trabalho no quilombo de Abacatal em Belém, afirma ter trabalhado com os desenhos como técnica de pesquisa, embora apresente ao longo de toda a tese apenas um desenho colorido exposto em sua capa e outro no corpus do trabalho, analisado pela pesquisadora que afirma não ter tido oportunidade de conversar com a criança que $o$ fez. Sanches (2014, p. 83, grifo nosso) afirma os desenhos entre os interesses das próprias crianças:

Constantemente, convidavam-me para jogar cartas, brincar de diversas coisas, fotografar, desenhar, contar histórias e piadas, tomar banho de rio, juntar e apanhar frutas das árvores e pouco se interessavam por conversas fora desses contextos.

Sanches (2014, p. 90) confirma, em diversos trechos de sua tese, ter recorrido aos desenhos, como revela o fragmento abaixo:

Mas, antes de começar a frequentar as casas ofereci para cada criança, aquela que já sabia escrever, um caderno para registrar as atividades cotidianas. Àquelas crianças que ainda não sabiam escrever, dei um álbum de papel para que tentassem reproduzir as atividades por meio de desenhos.

A antropóloga diz ainda que "ouvir a voz das crianças é ser capaz de compreender as diversas linguagens que elas empregam na comunicação com esse mundo" (Sanches, 2014, p. 92). Entretanto o que Sanches reforça em relação ao desenho desaparece na sua não inserção dos desenhos na tese.

Observamos que embora os desenhos tenham sido fundamentais no livro de Pires (2011) sobre mal-assombro, ilustrando inclusive a própria capa, eles são citados e referenciados ao longo do texto, mas só aparecem em anexos. Essa contradição aparece em quase todos os trabalhos que se utilizam de desenhos. Embora os desenhos infantis sejam a matéria-prima para as análises, sem dúvida, são preteridos em relação ao texto.

Sousa (2017a) optou na etnografia sobre a produção da pessoa capuxu por construir um capítulo que apresentava o Sítio Santa-Queimadas pela visão das 
crianças, em que as imagens foram expostas com legendas, precedidas em seu conjunto por um breve texto introdutório. Assim, após a exposição do capítulo sobre a história do povo e do sítio, no meio da obra, os desenhos das crianças ganham destaque aparecendo reunidos em um capítulo exclusivo.

Mendonça (2018) buscou entender como a aprendizagem acontece para as crianças no contexto educacional de um grupo, formado por crianças e adolescentes, que vivenciam o batuque como prática coletiva nas oficinas de percussão da Escola Viva Olho do Tempo em João Pessoa. Para isso, a pesquisadora se utilizou de desenhos:

Os desenhos que se fazem presentes neste trabalho também indicam formas ativas de contações, estes são expressões simbólicas que as crianças comumente vivenciam em suas experiências na infância, principalmente aquelas em idade escolar, e se revelam como uma comunicação social que brota a partir de um ato criativo sobre o que se quer contar, como uma semântica aberta de quem realiza, seja para si ou para quem observa [...] E é frente a isto que os desenhos aqui apresentados no decorrer deste trabalho são analisados como um emaranhado de fios que se entrelaçam revelando conhecimentos, historicidades, afetos, emoções e culturas que só puderam ser interpretados com o apoio das crianças. (Mendonça, 2018, p. 44).

Na versão final de sua dissertação, Mendonça (2018) utilizou os vários desenhos no corpus do texto, mas em geral eles ilustravam algo que acabara de ser dito pela autora, acompanhados de legendas simples.

Também Pastore (2020, p. 44), tendo como objetivo a compreensão do brincar e suas implicações enquanto atividade significativa das crianças, compôs uma etnografia em que afirma que em Mabotine, Moçambique, "o método por elas escolhido, em sua grande maioria, foi o desenho e como representar, nele, as suas histórias e vivências". Pastore afirma então que o esforço das crianças gerou 75 desenhos. Na versão final da tese, apenas dois desdes desenhos foram incluídos. Um terceiro desenho chega a ser mencionado e interpretado, mas sem ser inserido no texto.

Pimentel (2020) analisou a experiência de crianças e adolescentes com a doença falciforme na Paraíba, e elegeu os desenhos como meio para tal. Dentre as qualidades do trabalho está uma apresentação das crianças e adolescentes 
através de desenhos construídos por elas mesmas, numa espécie de autorretrato. Esses desenhos são acompanhados pelo perfil de cada família e criança descritos por Pimentel. O trabalho apresenta uma gama de desenhos distribuídos por todo o texto, revelando o percurso que a autora trilhou para chegar aos resultados.

Até que ponto consideramos a elaboração de desenhos, de fato, uma técnica de produção de dados tão legítima quanto as entrevistas, conversas informais, o uso de questionários ou grupos focais? Essa pergunta lembra-nos o texto de Favret-Saada (2005, p. 155, grifo nosso), no qual ela argumenta:

[...] meu trabalho põe em causa o fato de que a antropologia acha-se acantonada no estudo dos aspectos intelectuais da experiência humana, nas produções culturais do "entendimento", para empregar um termo da filosofia clássica. É - parece-me urgente, reabilitar a velha "sensibilidade", visto que estamos mais bem equipados para abordá-la do que os filósofos do século XVII.

Ou seja, podemos incluir na pesquisa antropológica outras abordagens metodológicas que nos permitam galgar outras sensibilidades para além daquelas que podem ser expressas através da linguagem concatenada? Talvez aí resida uma das importantes razões da dificuldade da penetração dos estudos com crianças pelo mainstream: o fato de que a comunicação com as crianças prescinde da fala. E como faremos, então - perguntamo-nos? Elas não falam, não podem falar (ou foram silenciados pelo viés da palavra?).

\section{Considerações finais}

Neste artigo dedicamo-nos a analisar os usos do desenho como técnica de pesquisa na antropologia e sua inserção nos textos antropológicos. Diante disso, selecionamos uma literatura existente sobre os desenhos que os apresentam como técnica de pesquisa. Para isso, analisamos o fato de a técnica de produção de desenhos ter sido utilizada nas pesquisas como um modo de se aproximar das crianças, utilização esta que se sobrepõe ao uso da ferramenta como modo de acessar o ponto de vista das crianças. Vimos, ainda, como diversas autoras defendem o uso do desenho combinado a outras técnicas de pesquisa como a 
observação direta e as conversas informais ou entrevistas com crianças sobre os desenhos por elas produzidos.

No que se refere à inserção dos desenhos nos textos antropológicos, destacamos a importância de se descrever os processos de produção dos desenhos, em que condições, lugares e tempos foram construídos, e a necessidade de colocá-los em lugar de destaque nos nossos textos, uma vez que encontramos na mesma ferramenta dois usos fundamentais: o de proporcionar o acesso a crianças de várias idades e ao mesmo tempo de traduzir leituras de mundo ou de acessar as suas narrativas.

Expomos aqui excelentes etnografias de pesquisadoras de/com crianças que afirmam ter utilizado desenhos como importante técnica de pesquisa, mas não os inserem no texto, e quando o fazem os colocam em anexos. Às vezes, quando eles vêm no corpo do texto não são explorados em sua potencialidade. Salvo raras exceções.

Avaliamos, portanto, que considerar a produção de desenhos como técnica legítima de pesquisa implica o reconhecimento e o respeito aos modos próprios de dizer de si e do mundo a sua volta que as crianças possuem. Pensamos que defender o uso da técnica unicamente como uma maneira de se aproximar, estar junto das crianças, é negligenciar a potencialidade da técnica e a sua capacidade de revelar aquilo que a retórica, o corpo ou os gestos não revelam. Ademais, se as crianças dão tamanha importância ao desenho e se comunicam ou informam algo através dele, eles devem ser considerados dignos de estar nos nossos textos finais. Para além de uma dádiva, uma moeda de troca. Embora nada disso esgote as possibilidades do desenho infantil enquanto técnica de investigação.

Cabe destacar que a antropologia, apesar de sua recente tradição no uso dos desenhos, parece tê-lo feito de maneiras diversas, o que reforça o potencial da técnica. Seja como uma senha de acesso às crianças, isto é, um passe para o campo; seja como um modo de diálogo com as crianças menores cuja fala não é ainda articulada; seja porque os desenhos dão pistas sobre algo a ser perseguido em campo, a antropologia utiliza a técnica sob diversas possibilidades de usos e compreensões. Essa possibilidade de usos múltiplos da mesma técnica reforça a importância dos desenhos na pesquisa etnográfica com crianças. 


\section{Referências}

BORDIN, F. B.; BUSSOLETTI, D. Desenhos infantis, culturas da infância e a pesquisa em educação. Educativa, Goiânia, v. 17, n. 2, p. 439-452, jul./dez. 2014.

CHRISTENSEN, P.; JAMES, A. Research with children: perspectives and practices. New York: Routledge, 2008.

COHN, C. O desenho das crianças e o antropólogo: reflexões a partir das crianças mebengokré-xikrin. [S. l.: s. n.], 2006. Paper apresentado. 25ª Reunião Brasileira de Antropologia, Goiânia, 2006.

COHN, C. A tradução de cultura pelos Mebengokré-Xikrin da perspectiva de suas crianças. In: REUNIÃO BRASILEIRA DE ANTROPOLOGIA, 27., 2008, Belém. Anais [...]. Belém: ABA, 2008. p. 1-10.

CORSARO, W. Entrevista com Willian Corsaro. [Entrevista concedida a] Fernanda Müller. Educação \& Sociedade, Campinas, v. 28, n. 98, p. 271-278, 2007.

CUNHA, S. M. da. Pesquisa com crianças: implicações teóricas, éticas e metodológicas. In: CONGRESO IBERO-AMERICANO EN INVESTIGACIÓN CUALITATIVA, 6., 2017. Atas [...]. [S. l.: s. n.], 2017. Disponível em: https://proceedings.ciaiq.org/index. php/ciaiq2017/article/view/1142/1108. Acesso em: 20 mar. 2020.

DAMATTA, R. O ofício do etnólogo ou como ter “Anthropological Blues”. In: NUNES, E. de O. (org.). A aventura sociológica. Rio de Janeiro: Jorge Zahar, 1978. p. 23-35.

DELGADO, A. C. C.; MÜLlER, F. Apresentação. Educação \& Sociedade, Campinas, v. 26, n. 91, p. 351-360, ago. 2005. Disponível em: http://dx.doi.org/10.1590/S010173302005000200002. Acesso em: 20 mar. 2020.

FARIA, A. L. G.; DEMARTINI, Z. B. F.; PRADO, P. D. (org.). Por uma cultura da infância: metodologias de pesquisa com crianças. Campinas: Autores Associados, 2009.

FARIA, A. L. G.; FINCO, D. (org.). Sociologia da infância no Brasil. Campinas: Autores Associados, 2011.

FAVRET-SAADA, J. Ser afetado. Tradução de Paula Siqueira. Cadernos de Campo, São Paulo, v. 13, n. 13, p. 155-161, 2005. Disponível em: https://www.revistas.usp.br/cadernosdecampo/article/view/50263. Acesso em: 20 mar. 2020.

FERREIRA, N. G. de B. Maternidade e crianças encarceradas: etnografando o dia de domingo do Presídio Maria Júlia Maranhão (João Pessoa - PB). 2020. Dissertação (Mestrado em Antropologia) - Centro de Ciências Humanas, Letras e Artes, Universidade Federal da Paraíba, João Pessoa, 2020. 
GIBIM, A. P. G.; MÜLLER, F. O que crianças pensam sobre família e relações de gênero?. Zero-a-Seis, Florianópolis, v. 20, n. 37 p. 76-94, jan./jun. 2018.

GOBBI, M. Desenhos e fotografias: marcas sociais de infâncias. Educar em Revista, Curitiba, n. 43, p. 135-147, jan./mar. 2012. Disponível em: http://www.scielo.br/pdf/er/ n43/n43a10.pdf. Acesso em: 20 mar. 2020.

GOLDBERG, L.; FROTA, A. M. M. C. O desenho infantil como escuta sensível na pesquisa com crianças: inquietude, invenção e transgressão na elaboração do mundo. Revista de Humanidades, Fortaleza, v. 32, n. 2, p. 172-179, jul./dez. 2017. Disponível em: https://periodicos.unifor.br/rh/article/view/7474/5545. Acesso em: 20 mar. 2020.

GRUBITS, S. A casa: cultura e sociedade na expressão do desenho infantil. Psicologia em Estudo, Maringá, v. 8, num. esp., p. 97-105, 2003. Disponível em: https://doi. org/10.1590/S1413-73722003000300012. Acesso em: 20 mar. 2020.

HORN, C. I. Pesquisa etnográfica com crianças: algumas possibilidades de investigação. Enfoques, Rio de Janeiro, v. 13, n. 1, p. 1-22, dez. 2013. Disponível em: https:// revistas.ufrj.br/index.php/enfoques/article/view/12624/8828. Acesso em: 20 mar. 2020.

JAMES, A. Giving voice to children's voices: practices and problems, pitfalls and potentials. American Anthropologist, [s. l.], v. 109, n. 2, p. 261-272, 2008. DOI: 10.1525/ aa.2007.109.2.261.

JAMES, A.; JENKS, C.; PROUT, A. Theorising childhood. Cambridge: Polity Press, 1998.

LIMA, J. de S.; SOUSA, E. L. de. Autonomia das crianças versus controle institucional: uma análise da agência infantil em uma casa abrigo de Imperatriz. Revista Pós Ciências Sociais, São Luís, v. 17, n. 33, p. 297-318, 2020.

LOWENFELD, V. A criança e sua arte. São Paulo: Editora Mestre Jou, 1977.

MEAD, M. Growing up in New Guinea. London: Penguin Books, 1963.

MEAD, M. Educación y cultura en Nueva Guinea. Barcelona: Paidos Studio, 1985.

MENDONÇA, K. J. R. No tempo dos tambores: os saberes ritmados pela infância na escola viva olho do tempo. 2018. Dissertação (Mestrado em Sociologia) - Centro de Ciências Humanas, Letras e Artes, Universidade Federal da Paraíba, João Pessoa, 2018.

MÈREDIEU, F. de. O desenho infantil. 14. ed. São Paulo: Cultrix, 2017. 
MONTEIRO, E. do N. J. As crianças Calon: uma etnografia sobre a concepção de infância entre ciganos no Vale do Mamanguape - PB. 2015. Dissertação (Mestrado em Antropologia) - Centro de Ciências Humanas, Letras e Artes, Universidade Federal da Paraíba, João Pessoa, 2015.

MONTEIRO, E. do N. J.; GOLDFARB, M. P. L. A infância Calon: notas sobre o "ser criança" entre os ciganos no Vale do Mamanguape - Paraíba, Brasil. Fragmentos de Cultura, Goiânia, v. 27, n. 1, p. 19-29, jan./mar. 2017.

MUELLER, B. "Tiro de bola”: uma etnografia de crianças, emoções e conflitos no Brasil e no México. 2019. Tese (Doutorado em Antropologia) - Instituto de Ciências Humanas e Filosofia, Universidade Federal Fluminense, Niterói, 2019.

MÜLLER, F.; CARVALHO, A. M. A. (org.). Teoria e prática na pesquisa com crianças: diálogos com William Corsaro. São Paulo: Cortez, 2009.

MÜLLER, F.; DUTRA, C. P. R. Percursos urbanos: (im)possibilidades de crianças em Brasília e Florianópolis. Educação em Foco, Juiz de Fora, v. 23, n. 3, p. 799-818, set./ dez. 2018. Disponível em: https://periodicos.ufjf.br/index.php/edufoco/article/ view/20103. Acesso em: 20 mar. 2020.

PASTORE, M. Di N. Brincar-brinquedo, criar-fazendo: entrelaçando pluriversos de infâncias e crianças desde o sul de Moçambique. 2020. Tese (Doutorado em Terapia Ocupacional) - Centro de Ciências Biológicas e da Saúde, Universidade Federal de São Carlos, São Carlos, 2020.

PAULA, M. E. de. O processo e o produto da pesquisa: a negociação do texto de pesquisa com as crianças. In: PEREIRA, R. M. R.; MACEDO, N. M. R. (org.). Infância em pesquisa. Rio de Janeiro: Nau, 2012. p. 223-235.

PIMENTEL, B. T. Colorindo conversas e desenhando histórias: experiências de crianças e adolescentes com doença falciforme na Paraíba. 2020. Dissertação (Mestrado em Sociologia) - Centro de Ciências Humanas, Letras e Artes, Universidade Federal da Paraíba, João Pessoa, 2020.

PIRES, F. Ser adulta e pesquisar crianças: explorando possibilidades metodológicas na pesquisa antropológica. Revista de Antropologia, São Paulo, v. 50, n. 1, p. 225-270, jan./jun. 2007. Disponível em: http://www.scielo.br/scielo.php?script=sci_arttext\& pid=S0034-77012007000100006. Acesso em: 20 mar. 2020.

PIRES, F. Quem tem medo de mal-assombro?. Etnográfica, Lisboa, v. 13, n. 2, p. 291-312, nov. 2009. Disponível em: https://journals.openedition.org/etnografica/1321. Acesso em: 20 mar. 2020. 
PIRES, F. Quem tem medo de mal-assombro?: religião e infância no seminárido nordestino. João Pessoa: UFPB; Rio de Janeiro: E-Papers, 2011.

PIRES, F.; SANTOS, P. O. S. dos. O uso de grupos focais na pesquisa etnográfica com crianças. Zero-a-Seis, Florianópolis, v. 21, n. 40, p. 318-342, set./dez. 2019. Disponível em: https://periodicos.ufsc.br/index.php/zeroseis/article/view/1980-4512.2019v2ln40p318. Acesso em: 20 mar. 2020.

SANCHES, M. do S. R. A. “No abacatal (também), uma flor”: um estudo antropológico sobre a relação criança \& trabalho. 2014. Tese (Doutorado em Ciências Sociais) Universidade Federal do Pará, Belém, 2014.

SANTOS, P. O. S. dos. A invenção da infância: o Programa Bolsa Família e as crianças da comunidade de Feira Nova (Orobó) no Agreste pernambucano. 2014. Dissertação (Mestrado em Antropologia) - Centro de Ciências Humanas, Letras e Artes, Universidade Federal da Paraíba, João Pessoa, 2014.

SANTOS, P. O. S. dos. Infância, políticas públicas e mudanças geracionais: um estudo socioantropológico na zona rural de Orobó. 2020. Tese (Doutorado em Ciências Sociais) - Universidade Federal de Campina Grande, Campina Grande, 2020.

SARMENTO, M. As culturas da infância nas encruzilhadas da segunda modernidade. In: SARMENTO, M.; CERISARA, A. Crianças e miúdos: perspectivas sociopedagógicas da infância e educação. Porto: Edições ASA, 2004. p. 9-34.

SARMENTO, M. J. Conhecer a infância: os desenhos das crianças como produções simbólicas. In: MARTINS FILHO, A. J. PRADO, P. D. (org.). Das pesquisas com crianças à complexidade da infância. Campinas: Autores Associados, 2011. p. 27-60.

SARMENTO, M. J.; TREVISAN, G. A crise social desenhada pelas crianças: imaginação e conhecimento social. Educar em Revista, Curitiba, ed. esp. n. 2, p. 17-34, set. 2017.

SEEGER, A. Os índios e nós. Rio de Janeiro: Campos, 1980.

SILVA, M. A. de M.; MELO, B. M. de. Desenhos e mapas: uma contribuição aos estudos migratórios. Espaço Plural, Marechal Cândido Rondon, ano 10, n. 20, p. 41-51, 2009. Disponível em: https://www.trama.ufscar.br/desenhos-e-mapas-uma-contribuicao-aos-estudos-migratorios/. Acesso em: 20 mar. 2020.

SOUSA, E. L. Nomear é trazer à existência: a onomástica (de crianças e de bichos) e os apelidos na produção da pessoa capuxu. Campos, Curitiba, v. 15, n. 1, p. 71-97, 2014.

SOUSA, E. L. As crianças e a etnografia: criatividade e imaginação na pesquisa de campo com crianças. Iluminuras, Porto Alegre, v. 16, n. 38, p. 140-164, jan./jul. 2015.

SOUSA, E. L. Umbigos enterrados: corpo, pessoa e identidade capuxu através da infância. Florianópolis: EDUFSC, 2017a. (Coleção Brasil Plural/Instituto Brasil Plural-IBP). 
SOUSA, E. L. De passagem: uma análise do fenômeno "os Meninos do Trem" da Estrada de Ferro Carajás. Relatório Final de Projeto de Pesquisa apresentado à Fundação de Amparo a Pesquisa e ao Desenvolvimento Científico e Tecnológico do Estado do Maranhão. São Luís: Fapema, 2017b.

SOUSA, E. L. Autonomia do universo infantil versus autonomia infantil: a agência das crianças no contexto camponês capuxu. Temáticas: Revista de Pós-Graduandos em Ciências Sociais da Unicamp, Campinas, n. 51, p. 181-182, 2018. Disponível em: https://econtents.bc.unicamp.br/inpec/index.php/tematicas/article/ view/11633/6946. Acesso em: 20 mar. 2020.

SOUSA, E. L. As crianças e as linhas de transmissão em São Luís: Perspectivas metodológicas de uma pesquisa sobre representações infantis. Mediações, Londrina, v. 24, n. 2, p. 307-335, maio/ago. 2019. Disponível em: http://www.uel.br/revistas/uel/index. php/mediacoes/article/view/35291/pdf. Acesso em: 20 mar. 2020.

SPIVAK, G. C. Pode o subalterno falar?. Tradução do original em inglês: Sandra Regina Goulart Almeida, Marcos Pereira Feitosa e André Pereira Feitosa. Belo Horizonte: Editora UFMG, 2010.

TASSINARI A. M. I. Produzindo corpos ativos: a aprendizagem de crianças indígenas e agricultoras através da participação nas atividades produtivas familiares. Horizontes Antropológicos, Porto Alegre, ano 21, n. 44, p. 141-172, jul./dez. 2015. Disponível em: http://www.scielo.br/scielo.php?script=sci_arttext\&pid=S0104$-71832015000200141 \& l a n g=p t$. Acesso em: 20 mar. 2020.

TASSINARI, A. M. I. "A casa de farinha é a nossa escola": aprendizagem e cognição galibi-marworno. Revista Política \& Trabalho, João Pessoa, v. 1, n. 43, 2016. Disponível em: https://periodicos.ufpb.br/ojs/index.php/politicaetrabalho/article/view/24748. Acesso em: 20 mar. 2020.

TOREN, C. Making sense of hierarchy: cognition as social process in Fiji. London: Athlone Press, 1990.

TOREN, C. Making history: the significance of childhood cognition for a comparative anthropology of mind. Man, New Series, [s. l.], v. 28, n. 3, p. 461-478, 1993.

TOREN, C. Como nos tornamos quem somos: entrevista com Christina Toren. [Entrevista cedida a] Aline de Paula Regitano. Proa: Revista de Antropologia e Arte, Campinas, v. 9, n. 1, 2019. Disponível em: https://www.ifch.unicamp.br/ojs/index.php/proa/ article/view/3593. Acesso em: 20 mar. 2020.

Recebido: 31/03/2020 Aceito: 04/03/2021 | Received:3/31/2020 Accepted:3/4/2021 